\title{
MercadoSI: Um jogo de tabuleiro para o ensino de Sistemas de Informação
}

\author{
Rennan J. M. Silva ${ }^{1}$, Wander L. V. Azevedo ${ }^{1}$, Roberto P. Nascimento ${ }^{1}$, Carla M. C. \\ Paxiúba $^{1}$ \\ ${ }^{1}$ Programa de Computação - Universidade Federal do Oeste do Pará (UFOPA) \\ Rua Vera Paz S/N - 68.035-110 - Santarém - PA - Brasil \\ \{rennan.silva, roberto.nascimento, carla.paxiuba\} eufopa.edu.br, \\ wander.azevedo0610@gmail.com
}

\begin{abstract}
The course of Information Systems (IS) has a close relationship with the market and with the management area, however some disciplines involves intensive theoretical approach. To improve teaching/learning process in these disciplines, one possibility is the use of educational games in order to attract the students' attention and improve their performance. This paper discusses the development of a board game based on "Monopoly game", contextualizing the area of information systems and the application of its contents. The reports of the students show that this was a funny activity, assisting in the integration of students and review of proposed content, making class more attractive and efficient.
\end{abstract}

Resumo. $O$ curso de sistemas de informação (SI) possui uma relação íntima com o mercado e com a área de administração, entretanto algumas disciplinas envolvem abordagem teórica intensiva. Para melhorar o processo de ensino aprendizagem nessas disciplinas, uma das possibilidades é a utilização de jogos educacionais, a fim de atrair a atenção dos alunos e melhorar seu desempenho. Este artigo aborda o desenvolvimento de um jogo de tabuleiro, baseado no jogo "Banco Imobiliário", contextualizando a área de SI bem como a aplicação de seu conteúdo. Os relatos dos alunos demonstram que esta foi uma atividade divertida, auxiliando na integração entre os alunos e na revisão do conteúdo proposto, tornando a aula mais atrativa e eficiente.

\section{Introdução}

Um dos principais problemas enfrentados no ensino de nível superior, especificamente nos cursos de Ciência da Computação, é assegurar o fator motivação dos alunos na maioria das disciplinas do curso [Silva e Martins 2007]. Isso acontece porque, nessa área, grande parte dos componentes curriculares tem conteúdo demasiado teórico e também porque a técnica dominante de instrução nos cursos de graduação em Computação são as tradicionais aulas expositivas [Battistella et. al. 2014].

Nesse contexto, uma abordagem alternativa às aulas tradicionais é a utilização de jogos, pois, estes, ajudam a construir novas descobertas, desenvolvem e enriquecem a personalidade e simbolizam um instrumento pedagógico que leva ao docente a condição de condutor, estimulador e avaliador da aprendizagem. 
Além disso, os jogos e brincadeiras são excelentes oportunidades de mediação entre o prazer e o conhecimento historicamente constituído, já que o lúdico é, eminentemente, cultural. Por meio da ótica do psicólogo suíço Jean Piaget, pode-se notar que a concepção dos jogos não é apenas uma forma de desafogo ou entretenimento para gastar energias das pessoas, mas meios que contribuem e enriquecem $o$ desenvolvimento intelectual [Piaget 1976]. O caráter de integração e interação contidas nas atividades lúdicas também permite a integração do conhecimento com ações práticas, [Chaguri 2004],

Este trabalho apresenta um jogo de tabuleiro a ser utilizado na revisão de conteúdo de disciplinas teóricas de modo que os discentes, a partir das estratégias proporcionadas pelo jogo, possam rever o conteúdo de forma mais interessante, ajudando no processo de fixação de conceitos e, consequentemente, melhorando sua aprendizagem.

O restante deste artigo está organizado da seguinte forma: A seção 2 apresenta o contexto de jogos educacionais e a sua utilização no ensino de computação. Na seção 3 é feita descrição do jogo, suas partes, o processo de desenvolvimento e as regras do jogo. O relato da experiência com aplicação do jogo em sala de aula, bem como os resultados qualitativos são apresentados na seção 4 e, por fim, a seção 5 apresenta as considerações finais do trabalho em questão.

\section{Utilização de jogos educacionais no processo de ensino aprendizagem}

Os jogos educacionais ajudam a criar um entusiasmo sobre o conteúdo a ser trabalhado, a fim de considerar os interesses e as motivações dos discentes em expressar-se, agir e interagir nas atividades lúdicas realizadas na sala de aula. Segundo Grando (2001), no contexto de ensino-aprendizagem, a utilização de jogos implica em vantagens e desvantagens, sendo as principais vantagens:

- Fixação de conceitos já aprendidos de uma forma motivadora para o aluno;

- Introdução e desenvolvimento de conceitos de difícil compreensão;

- Aprender a tomar decisões e saber avaliá-las;

- Significação para conceitos aparentemente incompreensíveis;

- Propicia o relacionamento de diferentes disciplinas (interdisciplinaridade);

- Requer a participação ativa do aluno na construção do seu próprio conhecimento;

- Favorece a socialização entre alunos e a conscientização do trabalho em equipe;

- A utilização dos jogos é um fator de motivação para os alunos;

- Favorece o desenvolvimento da criatividade, de senso crítico, da participação, da competição "sadia", da observação, das várias formas de uso da linguagem e do resgate do prazer em aprender;

- As atividades com jogos podem ser utilizadas para reforçar ou recuperar habilidades necessárias para os alunos. Útil no trabalho com alunos de diferentes níveis;

- Permitem ao professor identificar, diagnosticar alguns erros de atitudes e dificuldades dos alunos;

Portanto, o jogo é uma atividade que tem valor educacional intrínseco. Leif diz que "jogar educa, assim como viver educa: sempre sobra alguma coisa" [Leif e Brunelle 
apud. Passerino, 1998], sendo assim justificada a importância da utilização dos jogos no processo ensino aprendizagem.

Diversos trabalhos foram propostos na literatura, adotando os jogos para facilitar o processo de ensino aprendizagem. Dentre esses, estão o trabalho de Battistella [Battistella et. al. 2014] que faz uma revisão sistemática da literatura de como os jogos educacionais são desenvolvidos e qual o processo utilizado para sua criação. Alguns dos trabalhos analisados pelo autor não apresentam um processo bem definido de criação. Por outro lado, Silva e Martins [Silva e Martins 2007], propõem o ensino de Ciência da Computação através da utilização de jogos, aplicando os jogos digitais para desenvolver competências e habilidades exigidas pelas ementas das principais disciplinas do curso. Já Baker [Baker et. al. 2005] elaborou um jogo de cartas educacional que simula o processo de engenharia de software para auxiliar no processo ensino aprendizagem da disciplina de engenharia de software. Por sua vez, Herpich [Herpich et. al. 2013], utiliza jogos sérios, que são ambientes simulados, no ensino das disciplinas de computação para auxiliar o desenvolvimento cognitivo dos alunos.

\section{MercadoSI: Um jogo de tabuleiro para o ensino de Sistemas de Informação}

Diante do cenário apresentado, surgiu a ideia do desenvolvimento de um jogo a partir da adaptação do jogo mundialmente conhecido "banco imobiliário" ao conteúdo da disciplina Tópicos Especiais em Sistemas de Informação (SI), ministrada no curso de Bacharelado em Sistemas de Informação, tendo em vista dois fatores: primeiro, que a TI (Tecnologia da Informação) deve se alinhar aos objetivos organizacionais para cumprir sua função principal; segundo, que o objetivo de uma empresa é gerar lucro, fazendo com que esse objetivo se confunda com o objetivo do próprio jogo proposto [Laudon e Laudon 2011].

Para cumprir os objetivos de aprendizagem, o jogo foi pensado para ser aplicado em uma aula de revisão de conteúdo, onde se pudesse criar um exercício a ser respondido, oralmente, pelos jogadores, à medida que o jogo fosse acontecendo. $\mathrm{O}$ objetivo do jogo é o jogador se tornar o empresário de TI mais rico, monopolizando o mercado de sistemas de informação, negociando seus sistemas, alugando, vendendo, investindo, com muito cuidado para não ir à falência. Para que o jogo aconteça, é necessária a elaboração de alguns elementos e adaptação de outros, dentre eles: 1 (um) tabuleiro; 6 (seis) analistas que percorrem o tabuleiro; 20 (vinte) cartas sorte-revés que apresentam situações e influenciam os negócios na área de TI; 1 (um) questionário contendo 30 (trinta) perguntas sobre o assunto a ser revisado; dinheiro.

\subsection{Processo de desenvolvimento}

O desenvolvimento deste jogo seguiu as etapas levantadas por [Battistella 2014], passando pelas fases de Análise, Projeto, Desenvolvimento, Execução e Avaliação.

\subsubsection{Análise}

Para averiguar se o jogo seria útil ou não dentro da disciplina, foi necessário o conhecimento do jogo-base (O Banco Imobiliário), seu tabuleiro, regras e tipos de

\footnotetext{
${ }^{1}$ http://estrela.com.br/brinquedo/banco-imobiliario/
} 
jogadas. Nessa etapa, foram identificados os pontos em comum com a disciplina e definidas adaptações a serem feitas para aplicar a ideia do jogo ao contexto desejado. Foram também desenvolvidos os objetivos de aprendizagem com a utilização do jogo.

\subsubsection{Projeto}

A partir do momento que se teve o conhecimento aprofundado do jogo e foram definidos os objetivos de aprendizagem, foi possível estabelecer o desenho do tabuleiro, fazendo as devidas adaptações, o tipo de conteúdo das cartas sorte-revés e alteração na forma de jogar, adicionando o questionário antes de cada jogada. De modo geral foi feita equivalência em cada um dos itens do jogo original ficando da seguinte forma:

- O tabuleiro que era composto de terrenos em ruas e avenidas deu lugar ao direito de oportunidade de desenvolvimento de determinado tipo de sistema de informação (SI), de modo que cada tipo de SI possua 3 (três) módulos.

- Peões do jogo banco imobiliário, passaram a representar os analistas de sistemas os quais cada jogador dispunha de um e que percorrem o tabuleiro, podendo implementar ou não determinados módulos dos softwares disponíveis.

- As companhias do jogo original foram substituídas por companhias das áreas de tecnologia, tornando o conteúdo mais aproximado à realidade da turma.

- A prisão foi mantida dando simbologia de implementação de função ilegal por parte de um Analista de Sistemas.

- Além disso, para ter direito à implementação de versão de determinado módulo, foi estabelecido que o jogador respondesse uma pergunta do questionário, o que dá maior oportunidade de ganhar o jogo aquele que dominar melhor o conteúdo.

\subsubsection{Desenvolvimento}

De posse do concebido anteriormente, na fase de desenvolvimento, ocupou-se da criação do tabuleiro propriamente dito com todas as suas partes, da criação das cartas sorte-revés, da elaboração do questionário e aquisição e desenvolvimento de elementos chaves para a execução do jogo como os peões que representariam os analistas, os títulos de oportunidade, a melhoria de versões e o dinheiro propriamente dito. É importante destacar também que os valores utilizados foram tirados como referência o jogo original.

\subsubsection{Execução}

Estando o jogo todo desenvolvido, foi feito um teste de jogabilidade em que cada autor fez o papel de um jogador e verificou-se que o jogo atendia aos objetivos traçados. Dessa forma, o jogo foi aplicado em uma aula de revisão de conteúdo, em uma turma do curso de Bacharelado em Sistemas de Informação.

\subsubsection{Avaliação}

A execução do jogo foi gravada em vídeo, com o consentimento dos alunos e a avaliação qualitativa foi feita com base, tanto em atitudes no momento do jogo, como por relatos feitos e gravados após a atividade. 


\subsection{Partes do Jogo}

O jogo é composto por diversas partes, dentre as quais o tabuleiro é o local onde os analistas percorrem, a fim de ir desenvolvendo sistemas. Dentro deles existem alguns elementos, como é mostrado na Figura 1:

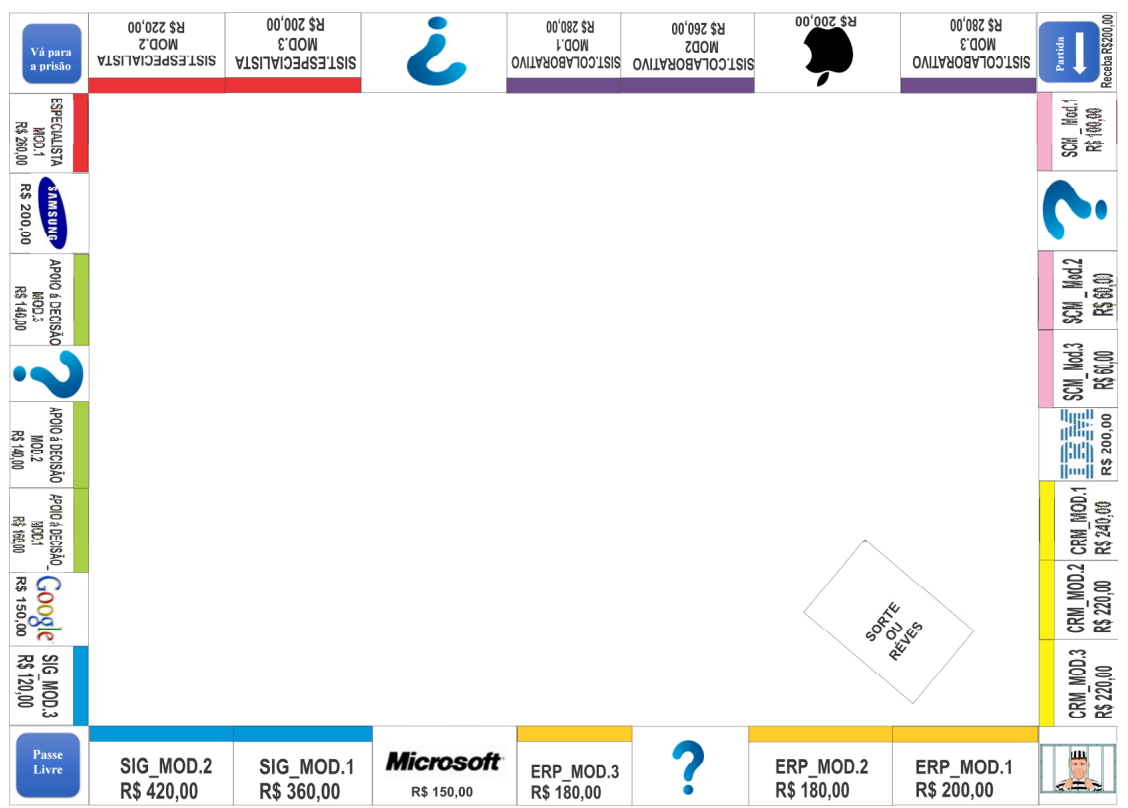

Figura 1. Tabuleiro do Jogo

Ponto de Partida: Local de partida onde todos os jogadores iniciam com seu analista. Para saber quem começa jogando, cada jogador lança um par de dados. Aquele que obtiver o maior número, na soma dos resultados, será o primeiro a jogar, sendo que o jogo foi projetado para jogarem de 2 a 6 pessoas.
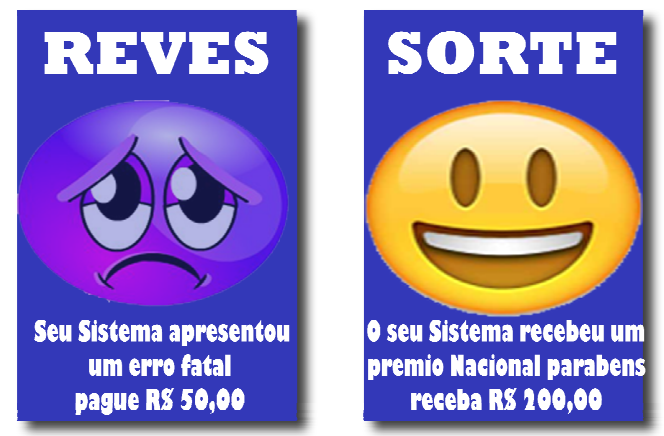

Figura 2. Demonstração de cartas sorte-revés

Tipos de Sistemas de Informação: Dentro do tabuleiro, existem diversos espaços dispostos de modo colorido, onde cada cor representa um tipo de sistema de informação (SI), totalizando sete tipos de SI (sistema de gestão da cadeia de suprimentos - SCM, sistema de relacionamento com o cliente - CRM, sistemas integrados de gestão - ERP, sistemas de informação gerencial - SIG, sistemas de apoio à decisão, sistemas especialistas e sistemas colaborativos). Cada tipo de sistema de informação é composto por três módulos dispostos de forma próxima um do outro. 
Carta Sorte-revés: Simbolizado pelo espaço com ponto de interrogação, quando o jogador para num espaço desses, deve escolher uma carta sorte-revés, conforme apresentado na Figura 2, dentre as vinte possibilidades, nas quais apresentam fatores externos, que influenciam nos sistemas de informações e em seu desempenho, gerando lucro ou prejuízo.

Baralho de perguntas: Baralho (Figura 3) contendo questões de exercício de revisão do conteúdo ministrado em sala de aula. Essas perguntas são o passaporte para o jogador ter oportunidade de prosperar no jogo, fazendo com que os jogadores que compreenderam melhor o conteúdo consigam prosperar de forma mais rápida.

Empresas de TI: No tabuleiro, existem alguns espaços que contemplam grandes empresas de porte mundial na área de tecnologia (Apple, Microsoft, Google, IBM e Samsung), às quais o jogador pode se associar, quando parar no espaço de uma dessas empresas.

Prisão: Para dar um pouco mais de emoção ao jogo e caracterizar rotinas e situações ilegais que podem ser desenvolvidas em SI, existe um espaço denominado "prisão", no qual o jogador deve ficar quando para no espaço "vá para a prisão" por três jogadas ou quando tirar três vezes um par de valores iguais nos dados. Para sair da prisão o jogador deve tirar um par de valores iguais nos dados ou, se isso não acontecer em três rodadas, pagar a fiança estabelecida na quarta rodada.

Títulos de oportunidade: Um título de oportunidade, conforme mostrado na Figura 3, representa a oportunidade de um jogador em prosperar e investir em seu negócio de SI, tanto desenvolvendo, quanto melhorando a versão de seu módulo. Para ter um título de oportunidade, o jogador deverá escolher uma carta no baralho de perguntas sobre o assunto e respondê-la corretamente. Após isso, deverá colocar a carta escolhida na parte debaixo do baralho.

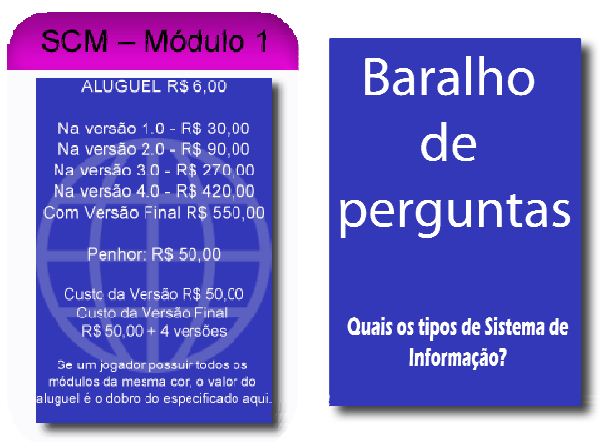

Figura 3. Carta de título de oportunidade e Carta de baralho de perguntas

\subsection{Regras e como jogar}

No início do jogo, cada jogador recebe a quantia de $\mathrm{R} \$ 2.658,00$ (dois mil, seiscentos e cinquenta e oito reais) para jogar como quiser. A partir daí, os jogadores disputam nos dados quem começa. Aquele que tirar o maior número na soma dos dados é o que inicia a partida. Então, o primeiro jogador lança os dois dados, conta o total de pontos que saiu, e avança com seu Analista no sentido da seta o número de casas obtidas nos dois dados. Será, então, a vez do próximo jogador à esquerda, que fará o mesmo e, assim por diante. Toda vez que alguém tirar uma dupla nos dados (1-1, 2-2 e assim por diante), 
anda o número de casa e pode jogar os dados de novo, logo em seguida. Se tirar novamente uma dupla, pode andar novamente e jogar os dados mais uma vez. Mas se tirar dupla pela terceira vez, o jogador vai para a prisão. Assim, deverá colocar seu Analista no espaço “prisão".

Conforme o espaço em que parar com seu Analista, poderão acontecer diversas situações com o jogador. Num só espaço podem parar vários Analistas, ao mesmo tempo. E conforme o espaço em que o Analista parar, o jogador poderá desenvolver um módulo de sistema, fazer negócio (comprar ou alugar), tirar uma carta de SORTEREVÉS ou ir preso. As explicações para cada espaço estão detalhadas a seguir.

Toda vez que parar em espaço de módulos de sistema e/ou companhias de tecnologia o jogador pode desenvolver aquele módulo (se ninguém ainda tiver comprado este direito) e/ou tornar-se sócio de companhias pelo preço indicado no tabuleiro. Entretanto, essa operação só poderá ser feita mediante a retirada de uma carta de um baralho de perguntas e em caso de resposta correta. É importante destacar que aqueles jogadores que melhor compreenderam o conteúdo terão oportunidade de progredir mais rapidamente no jogo, pois terão o direito de oportunidade liberado, para que desenvolvam os módulos de sistemas dispostos no tabuleiro.

Ponto de partida: Toda vez que passar pelo ponto de partida um jogador tem direito a receber R \$ 200,00 do banco como prêmio, exceto quando o jogo está começando.

Sistemas e Companhias com donos/sócios: Se um jogador parar num sistema ou companhia que já tenha dono terá que pagar ao sócio/desenvolvedor a quantia marcada no título de oportunidade: se for sistema, deve pagar a quantia indicada em aluguel; se for companhia, deve pagar a quantia indicada em taxa multiplicada pelo total obtido nos dados.

Desenvolvendo Sistemas: Ao parar em cima de um espaço de módulo de sistema, um jogador poderá comprar o título de oportunidade para desenvolvê-lo. Se parar novamente em um módulo ao qual já possua o título de oportunidade, pode incrementar a versão do módulo desenvolvido, podendo implementar até 4 (quatro) versões. Quando tiver quatro versões implementadas, o jogador poderá implementar uma versão final deste sistema.

Versão final de sistema: Um jogador pode construir a versão final do sistema e lucrar com isso. Para isso, deve primeiro construir quatro versões num mesmo módulo do sistema e depois vendê-las ao banqueiro pela metade do preço indicado no título de oportunidade. Para desenvolver uma versão final, deve-se pagar ao banqueiro a quantia indicada no título de oportunidade.

O jogador que parar nos módulos de sistemas já desenvolvidos deverá pagar um aluguel. Quanto mais versões, mais alto o valor do aluguel. Quando o banco não possuir mais títulos de oportunidade e/ou versões para vender, os jogadores com interesse de compra terão, obrigatoriamente, que esperar para que outros jogadores vendam seus títulos e versões de volta ao banco. Em caso de uma disputa entre poucas versões de sistemas disponíveis no banco, o jogador que fizer a oferta mais alta fica com a versão.

Sempre que interessar, mesmo sem ser sua vez de jogar, o jogador pode trocar ou vender seus módulos e sistemas para outro jogador, por preços a combinar entre os 
dois jogadores. Caso queira vender ou trocar um sistema com versões, terá antes que vender as versões para o Banco, sendo que este só paga a metade do valor disposto no título de oportunidade.

Penhor: Quando precisar de dinheiro, um jogador pode penhorar seus módulos e sistemas, sem versões desenvolvidas, ou companhias no Banco. Se existirem versões neles, deve-se vender para o Banco pela metade do preço. Assim, o banqueiro ficará com o título e pagará o valor correspondente à penhora, marcado na carta do título. Para resgatar o penhor e receber de volta o módulo de sistema ou companhia, o jogador terá que pagar ao banqueiro o valor do penhor mais $20 \%$ (vinte por cento). Para propriedades penhoradas não será coletado o aluguel das mesmas. Nenhum outro jogador poderá comprar do Banco uma propriedade penhorada, exceto quando tiver a concordância do dono, por preço a combinar mais $20 \%$ (vinte por cento), pago ao Banco em forma de taxa de transação.

Pagamentos: Quando o dinheiro acaba, o jogador deverá obedecer a seguinte ordem de negociações:

1. Venda de versões de sistemas e versão final ao Banco pela metade do preço. Se, depois disso, ainda precisar de dinheiro, deve-se passar para o próximo módulo e, assim por diante, até conseguir o dinheiro que precisa.

2. Penhora ou venda de versões, módulos e/ou companhias. Pode-se, também, leiloar versões ou companhias aos demais jogadores. Caso ninguém queira comprar, o Banco pagará seu valor nominal.

Falência: Se mesmo após vender as versões e/ou versões finais, penhorar, vender ou leiloar os módulos, o jogador não conseguir pagar suas dívidas, ele irá à falência e sairá do jogo. Todo dinheiro conseguido será entregue ao credor (aquele jogador ao qual está devendo). Caso haja oportunidades penhoradas, o Banco deverá resgatá-las e o dinheiro obtido irá para o credor. Esses títulos penhorados devem ser colocados a leilão. Não poderá haver empréstimo de um jogador a outro.

Término do jogo: $\mathrm{O}$ jogo termina quando ficar apenas um jogador (os outros foram à falência). Somam-se, então, todos os valores que ele tem direito e desconta-se os penhorados. Alternativamente, os participantes poderão estipular um tempo máximo para o término do jogo. Ao finalizar este tempo, faz-se a contagem dos valores das notas, sistemas, versões e versões finais. Se existirem módulos penhorados, computa-se a metade do valor pago por eles. Aquele que possuir mais dinheiro é o vencedor.

\section{Aplicação do jogo e resultados}

O jogo foi desenvolvido com o propósito de utilização em aula de revisão da disciplina de Tópicos Especiais em Sistemas de Informação, que é ministrada no penúltimo semestre de curso de Bacharelado em Sistemas de Informação. Esta disciplina contempla a integração de tópicos estudados, separadamente, em outras disciplinas específicas tais como administração, banco de dados, redes de computadores aplicadas ao contexto dos Sistemas de Informação. Nela, o aluno consegue ter uma visão geral do que estudou, separadamente, e juntar as partes para alinhar os objetivos da Tecnologia da Informação aos objetivos organizacionais.

Ele foi aplicado em uma turma do Curso de Bacharelado em Sistemas de Informação, de modo que os alunos fossem jogadores que dispunham de seus analistas, 
percorrendo o tabuleiro e, com o professor, fazendo a tutoria e o papel do banqueiro no jogo, conduzindo o andamento e fazendo as perguntas sorteada por meio do baralho de liberação do título de oportunidade. A execução do jogo teve duração de 2 (duas) horas, sendo encerrado pelo tempo estipulado, de modo que nenhum dos jogadores "foi à falência".

No início, os alunos demonstraram-se tímidos, devido ao fato de ser algo que não havia sido realizado por eles durante o curso. Com o passar do tempo, foi observado que os jogadores foram aprendendo as regras, traçando estratégias e fazendo mais tentativas de respostas às perguntas-chaves. À medida que o jogo foi avançando, os alunos que, no início, estavam acanhados e apenas sentados foram criando expectativas e se empolgando, característica que foi observada quando, em alguns momentos, os alunos que, no início, pediam para os colegas moverem seu analista pelo tabuleiro, pois este estava muito longe, agora já se levantavam para movê-lo numa clara demonstração de empolgação e envolvimento à estratégia traçada.

Ao final foi feita entrevista com os alunos a fim de avaliar a estratégia utilizada para abordar a revisão, bem como saber a visão dos alunos em relação à utilização deste tipo de metodologia nas aulas do curso. Os discentes se mostraram receptivos às inovações e explicaram que esse tipo de iniciativa é louvável frente a disciplinas teóricas, que demandam o estudo de conteúdos e que, em aulas expositivas, é feito de modo cansativo.

Um dos pontos positivos levantados é que a utilização do jogo é uma maneira de abordar todo o conteúdo estudado de forma dinâmica e diferente. Além disso, o fato de o aluno responder ao questionário, oralmente, estimula a fixação do conteúdo, tendo em vista, que leva o aluno a refletir sobre o conteúdo enquanto joga.

Foi exposto também, por parte dos alunos, que a revisão do conteúdo é feita explicitamente, mas que, implicitamente, também se trabalha o conteúdo por meio do cenário do jogo, que foi todo adaptado ao conteúdo da área de sistemas de informação, aproveitando as semelhanças existentes, mas mantendo sua essência.

De modo geral, os objetivos da utilização da metodologia foram alcançados, tendo em vista a aplicação de avaliação posterior, em que todos os alunos tiveram nota média acima de 6,0 (seis), alcançando resultado satisfatório. Qualitativamente, o jogo agradou aos alunos, resultado que foi evidenciado quando estes foram questionados sobre a possibilidade de utilizar o mesmo jogo, no futuro, na mesma disciplina, onde todos assinalaram positivamente, dizendo que preferem esse tipo de aula à utilização de um exercício revisão tradicional apenas contendo perguntas e respostas.

\section{Considerações finais}

A educação no nível superior carece de estratégias de diversificar o ensino e melhorar a aprendizagem dos alunos. Os professores desse nível costumam usar aulas expositivas para apresentar os temas de disciplinas. A utilização de jogos educacionais é uma importante estratégia no desenvolvimento cognitivo dos alunos de modo a melhorar a aprendizagem. O trabalho proposto apresenta um jogo de tabuleiro adaptado ao contexto da disciplina de Tópicos Especiais em Sistemas de Informação do curso de Bacharelado em Sistemas de Informação utilizado na revisão de conteúdo. 
Apesar de o jogo ter sido aplicado no escopo de apenas uma disciplina do curso, os resultados apontam para a efetividade da estratégia o que faz com que se pretenda ampliar sua a utilização, aplicando-o em outras disciplinas e verificando os resultados obtidos. Além disso, também deve realizar-se estudos comparativos entre resultados obtidos por discentes que passam pelo processo tradicional de revisão de conteúdo teórico e discentes que realizam a revisão do conteúdo através do jogo MercadoSI;

Apesar da necessidade de ampliar o público alvo do jogo para melhor análise dos resultados obtidos, considera-se que os resultados do estudo de caso apresentado neste artigo foram positivos, sendo demonstrados, tanto pelas atitudes dos discentes, por seu depoimento posterior, e pelo rendimento dos discentes na avaliação, o que possibilitou melhoria na fixação dos conteúdos abordados no jogo.

\section{Referências}

Baker, A., Navarro, E. O., Van Der Hoek, A. (2005). "An experimental card game for teaching software engineering processes". Journal of Systems and Software, 75(1-2), $3-16$

Battistella, P. E., Wangenheim, C. G, Fernandes, J. M. (2014) "Como jogos educacionais são desenvolvidos?". Em: XXXIV Congresso da Sociedade Brasileira de Computação - WEI - XXII Workshop sobre Educação em Computação. Páginas 1445 a 1454.

Chaguri, J. P. (2004). "Jogos: uma maneira lúdica de se aprender a língua inglesa". Loanda. Disponível em: http://www.linguaestrangeira.pro.br/para_saber/jogos.html. Acesso em: 15/02/2015.

Chaves, Sandramara M. (2001) "A avaliação da aprendizagem no ensino superior: realidade, complexidade e possibilidades.” Em: MOROSINI, M. (Org.). Professor do ensino superior: identidade, docência e formação. Brasília: Editora Plano, 2001.

Grando, R. C. (2001). “O jogo na educação: aspectos didático-metodológicos do jogo na educação matemática”. Unicamp. Disponível em: <www.cempem.fae.unicamp.br/lapemmec/cursos/el654/2001/jessica_e_paula/JOGO. doc> Acesso em: 18/05/2003.

Herpich, F., Nunes, F., Jardim, R., Voss, G., \& Medina, R. (2013). Jogos Sérios na Educação: Uma Abordagem para Ensino-Aprendizagem de Redes de Computadores (Fase I). Nuevas Ideas En Informática Educativa TISE 2013, v. 9(Fase I), p. 617-620

Kenneth Laudon e Jane Laudon, (2011). "Sistemas de Informação Gerenciais”. Pearson, $9^{a}$ edição.

Passerino, L. M. (1998) "Avaliação de jogos educativos computadorizados". Taller Internacional de Software Educativo 98 - TISE' 98. Anais. Santiago, Chile.

Piaget J. (1976). Psicologia e pedagogia. Trad. Lindoso DA, Ribeiro da Silva RM. Rio de Janeiro: Forense Universitária.

Silva, R. E.; Martins, S. W. (2007). Ensino de Ciência da Computação através do desenvolvimento de jogos. Em: VII Congresso Iberoamericano de Informática Educativa. Páginas 1286 a 1295. 